\title{
Avaliação da durabilidade de processos fotocatalíticos aplicados como pós-tratamentos em substratos de argamassa
}

\author{
The durability of photocatalytic process applied as post \\ treatment in mortars
}

\section{Guilherme Custódio Garcia Junior Eduardo de Azevedo Botter Flávio Leal Maranhão}

\section{Resumo

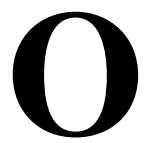

s processos fotocatalíticos estão sendo estudados e incorporados a sistemas construtivos objetivando melhoria da qualidade da água e do ar. No entanto pairam dúvidas sobre qual o grau de atuação da fotocatálise nos substratos e sobretudo por quanto tempo continua ocorrendo e qual sua intensidade. O método proposto consiste em, através de um pós-tratamento superficial associado a um processo fotocatalítico, obter a simultaneidade das ações dos efeitos hidrofóbicos e hidrofílicos. O presente artigo propõe avaliar a durabilidade de processos fotocatalíticos por meio de um programa experimental, em que corpos de provas de argamassa para revestimento externo após serem pós-tratados e manchados com soluções de azul de metileno $\left(\mathrm{C}_{16} \mathrm{H}_{18} \mathrm{~N}_{3} \mathrm{SCl}\right)$ na concentração de $1 \%$ em água deionizada e em álcool etílico $92,8^{\circ}\left(\mathrm{C}_{2} \mathrm{H}_{6} \mathrm{O}\right)$, foram submetidos a 200 ciclos de envelhecimento artificial (molhagem, exposição à radiações infravermelho e ultravioleta). Os resultados apontam: 1) o aumento da concentração de dióxido de titânio acelera os processos de degradação do azul de metileno; 2) os tratamentos superficiais com dispersões aquosas de $\mathrm{TiO}_{2}$ apresentaram queda de desempenho ao longo dos ensaios; 3 ) o hidrofugante à base de silicone mostrou um bom potencial como agente de fixação do semicondutor.

Palavras-chave: Fotocatálise. Durabilidade. Envelhecimento. Argamassa.

Revestimento.

\section{Guilherme Custódio Garcia \\ Junior \\ Universidade São Judas Tadeu} São Paulo - SP - Brasil

Eduardo de Azevedo Botter Universidade São Judas Tadeu São Paulo - SP - Brasil

Flávio Leal Maranhão Universidade de São Paulo São Paulo - SP - Brasil

Recebido em 26/08/13 Aceito em 14/08/15

\begin{abstract}
The photocatalytic processes are being studied and incorporated into building systems aiming at the improvement of the quality of water and air. However, there are doubts about the impact of the action of photocatalysis on substrates and especially about how long it continues occurring and about their intensity. The proposed method consists in using a surface post treatment associated with a photocatalytic process, in order to obtain the simultaneous actions of the hydrophilic and hydrophobic effect. This paper proposes to assess the durability of photocatalytic processes by means of an experimental program, where the bodies of the mortar tests for external coating after being post-processed and stained with methylene blue solution $\left(\mathrm{C}_{16} \mathrm{H}_{18} \mathrm{~N}_{3} \mathrm{SCl}\right)$ at a concentration of $1 \%$ in deionized water, and $92.8^{\circ}$ in ethyl alcohol $\left(\mathrm{C}_{2} \mathrm{H}_{6} \mathrm{O}\right)$ were subjected to 200 cycles of artificial aging (wetting, exposure to ultraviolet and infrared radiation). The results lead to: 1) increasing the titanium dioxide concentration of methylene blue accelerates the degradation process; 2) surface treatment with aqueous dispersions of $\mathrm{TiO}_{2}$ showed a decline in performance over the tests; 3) the hydrophobic silicone-based showed a good potential as semiconductor fixing agent.

Keywords: Photocatalysis. Durability. Aging. Mortars. Rendering.
\end{abstract}




\section{Introdução}

As superfícies das edificações sofrem mudanças em suas propriedades estéticas como consequência da interação com os agentes deletérios e de seu ciclo de vida. No caso de superfícies externas, sua intensidade é maior, ocasionando o surgimento de manchas em menor espaço de tempo como consequência da deposição da fuligem originada da queima de combustíveis fósseis e do crescimento de micro-organismos como fungos e algas.

As propriedades das superfícies e o microambiente em análise, exercem importante influência na cinética de manchamento, em que a presença de umidade provida pela água das chuvas contribui estabelecendo as condições ideais para a deposição de poluentes e a proliferação de micro-organismos. Assim, quanto maior o tempo em que a superfície permanece com elevado índice de umidade (do inglês, time of wetness) e maior a rugosidade superficial, mais rápidos e intensos serão os manchamentos.

Como formas de prevenção e retardo desse processo natural são empregados diversos métodos e materiais, com predominância para as soluções que reduzem o teor de água no substrato, como os tratamentos hidrofóbicos com silicones e acrílicos.

Objetivando desenvolver uma superfície com características autolimpantes, o presente trabalho propõe a associação de um tipo de silicone (siloxano), identificado por $\mathrm{WR}_{1}$, e um semicondutor, o dióxido de titânio $\left(\mathrm{TiO}_{2}\right)$ na forma de anatásio. Mantendo-se as propriedades hidrofóbicas dos silicones (impedindo a entrada e permanência de água nos corpos de prova) e através da incidência da radiação ultravioleta (UV) nas superfícies, pretendeu-se acelerar os processos oxidativos por meio da fotocatálise, promovendo a geração de radicais hidroxila $(\bullet \mathrm{OH})$, o que permite tornar o sistema capaz de mineralizar poluentes orgânicos como óxidos de nitrogênio, óxidos de enxofre, benzeno, tolueno, xileno e monóxido de carbono $\left(\mathrm{NO}_{\mathrm{x}}, \mathrm{SO}_{\mathrm{x}}, \mathrm{C}_{\mathrm{x}} \mathrm{H}_{\mathrm{x}} \mathrm{CH}_{\mathrm{x}}\right.$ e $\left.\mathrm{CO}\right)$ em formas não tóxicas como dióxido de carbono e água $\left(\mathrm{CO}_{2}\right.$ e $\mathrm{H}_{2} \mathrm{O}$ ), e reduzir o ângulo de contato das superfícies, facilitando o espalhamento da água de chuvas incidentes e, consequentemente, o carregamento das partículas das sujidades modificadas pela fotocatálise heterogênea.

Por ser um método ainda novo, existem dúvidas quanto à durabilidade do sistema. Nesse sentido, este trabalho tem por objetivo avaliar a durabilidade dos processos fotocatalíticos aplicados como pós-tratamento em argamassas submetidas a envelhecimento artificial.

\section{Revisão bibliográfica}

A fotocatálise é um processo natural que ocorre em semicondutores quando excitados por radiação ultravioleta, liberando energia capaz de degradar compostos orgânicos e micro-organismos. Sua descoberta ocorreu na década de 70, no Japão, quando o pesquisador Honda e seu aluno Fujishima, com o objetivo de criar sistemas para tratamento de água mais eficientes, descobriram que alguns semicondutores são capazes de reduzir a água em hidroxila e oxigênio quando incididos por radiação ultravioleta (MILLS; WANG; MCGRADY, 2006).

A aplicação da técnica para a construção civil teve seu início na década de 90 do século passado, quando, novamente no Japão, empresas e universidades iniciaram os testes em concretos e placas cerâmicas. Desde então o interesse em aplicar a técnica em outros materiais tem crescido em todo o mundo, principalmente por conta do grande potencial de tornar as superfícies autolimpantes e pelo fato de possibilitar a neutralização de partículas poluentes como $\mathrm{NO}_{\mathrm{x}} \mathrm{e}$ VOC (tolueno, xileno), tornando tais compostos menos agressivos em meios urbanos (FOLLI, 2010).

Atualmente já existe uma gama de produtos comercializados que se baseiam nos processos fotocatalíticos, sendo a grande maioria destinada a produtos não porosos. Especificamente para o caso dos materiais cimentícios, é uma técnica que já mostrou grande potencial em reduzir a proliferação de micro-organismos (BONETTA et al., 2007; KURTH, 2008) e em degradar agentes manchantes orgânicos (FOLLI et al., 2009; OHAMA; VAN GEMERT, 2011).

Nas argamassas a forma mais comum é por meio de adição, inicialmente às matérias-primas (MAGGOS et al., 2008), apesar de ser de conhecimento que apenas as partículas presentes na superfície que recebem radiação UV sejam fotoativadas e que o processo de carbonatação promove contínua perda de eficiência (LACKHOFF et al., 2003; DIAMANTI et al., 2013).

Uma alternativa é a aplicação como póstratamento, em que a presença de um agente de fixação é importante para garantir a adesão das partículas do semicondutor ao substrato e impedir o desprendimento precoce de partículas (DIAMANTI; ORMELLESE; PEDEFERRI, 2008). Nesse caso, o uso de agentes inorgânicos é o mais adequado, por não serem vulneráveis à 
degradação desencadeada pela fotocatálise atribuída ao semicondutor (GUO et al., 2013). Tanto para a adição à mistura como para o póstratamento, as questões de durabilidade do sistema geram dúvidas, visto que poucos trabalhos publicados apresentam dados quantitativos sobre o assunto (GUROL, 2006).

Por ser um processo natural que depende apenas da excitação de elétrons pela incidência luminosa nas superfícies e posterior liberação da energia da bandgap através dos raios UV, é de se esperar que não haja alteração de seu desempenho ao longo do tempo. Autores como Cassar (2004) e Vallée et al. (2004), com base em estudos em ambiente laboratorial e em escala piloto, afirmam que não há redução da atividade fotocatalítica com o passar do tempo. Porém, outros trabalhos vêm apresentando resultados contrários (RAO; SUBRAHMANYAM; BOULE, 2004; YU, 2015; POON; CHEUNG, 2007).

\section{Materiais e métodos}

Toda a pesquisa foi realizada em escala laboratorial, onde corpos de prova de argamassa para revestimento externo foram submetidos a ciclos de envelhecimento artificial, recebendo a incidência da radiação infravermelho (IV), água e radiação ultravioleta (UV), conforme representado pela Figura 1. O propósito em escolher um traço de argamassa foi reproduzir um substrato que promovesse as condições mais desfavoráveis para um revestimento cimentício, com baixa resistência mecânica, elevadas porosidade, rugosidade e absorção, permitindo a retenção de água e a deposição do agente contaminante, independentemente das incidências das agressões ao substrato, logo mais suscetíveis ao surgimento de manchas. Outros tipos de traços de frequente emprego na produção de artefatos cimentícios poderiam ser menos afetados pelas degradações impostas pelo programa experimental, e sobretudo o tratamento proposto visa melhorar o desempenho de qualquer superfície de matriz cimentícia com acabamento aparente, ou seja, sem receber outro tipo de revestimento protetor ou estético, como tintas e vernizes. Dessa forma, definido o tipo de matriz, todos os corpos de prova moldados foram posicionados em um ângulo de $110^{\circ}$ em relação à base horizontal e distantes $40 \mathrm{~cm}$ das fontes de radiação. $\mathrm{O}$ ciclo de molhagem foi realizado por meio de água corrente a uma vazão de $0,3 \mathrm{~L} / \mathrm{min}$, uniformemente distribuída pelas superfícies e com recirculação. A temperatura superficial dos corpos de prova apresentou variação entre 20 e $50{ }^{\circ} \mathrm{C}$; a umidade relativa do ar (URA) variou entre $60 \%$ e $100 \%$, e a temperatura do ambiente entre 25 e 30 ${ }^{\circ} \mathrm{C}$, onde o equipamento de envelhecimento artificial permaneceu em operação de forma ininterrupta durante todo o período de exposição dos corpos de prova (Figura 2).

Figura 1 - Sequência dos ciclos utilizados no programa experimental

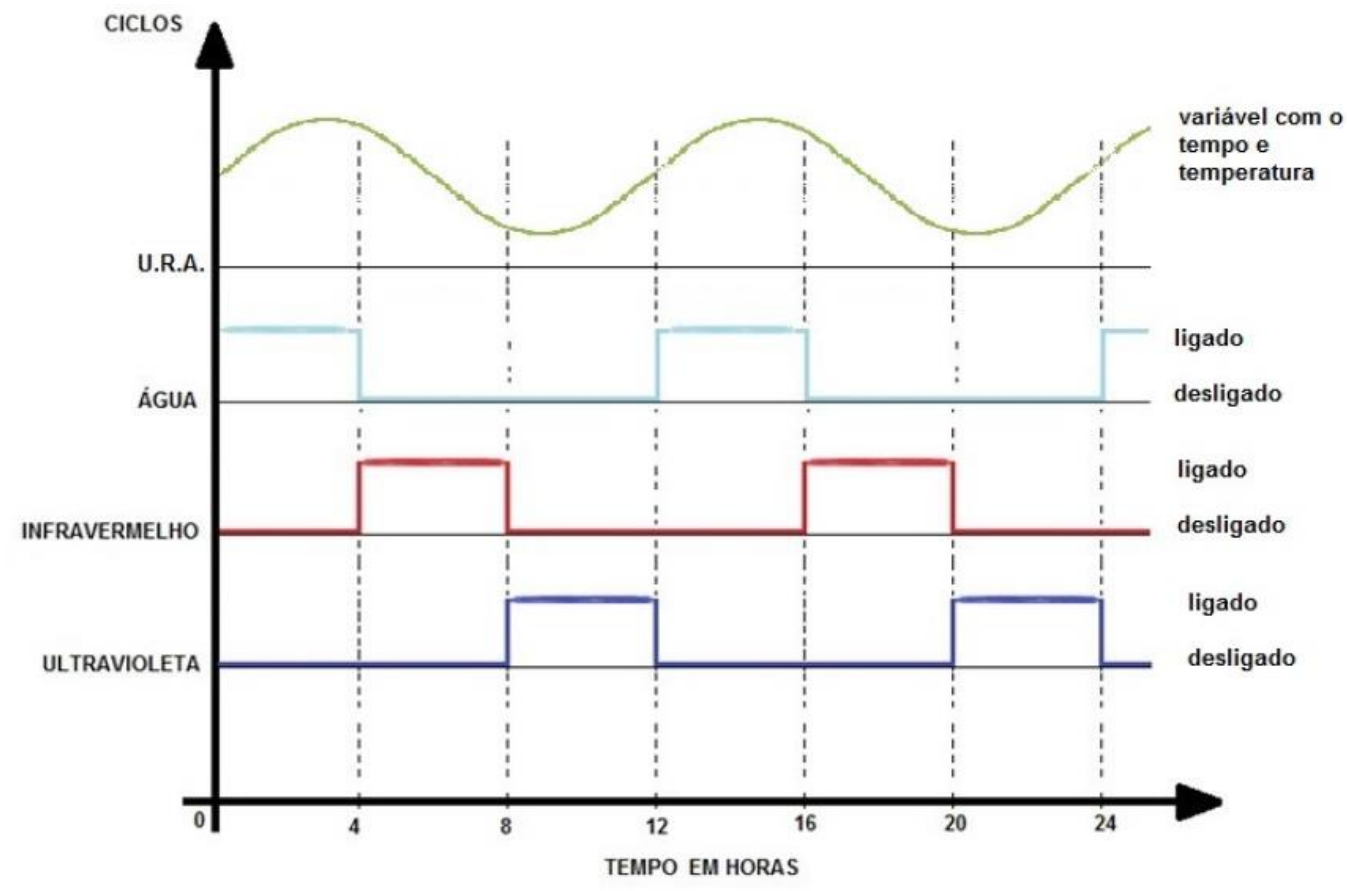


Figura 2 - Imagens do equipamento ao longo dos ciclos de envelhecimento artificial

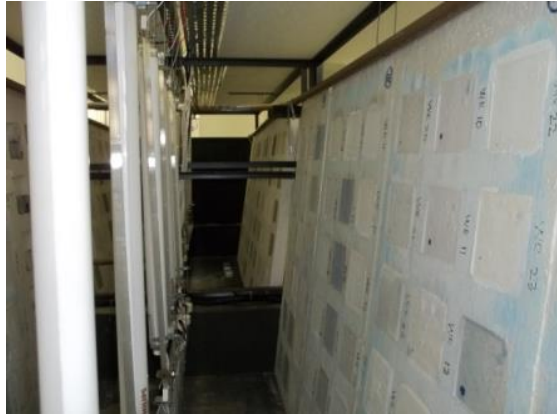

(a) Início do ciclo

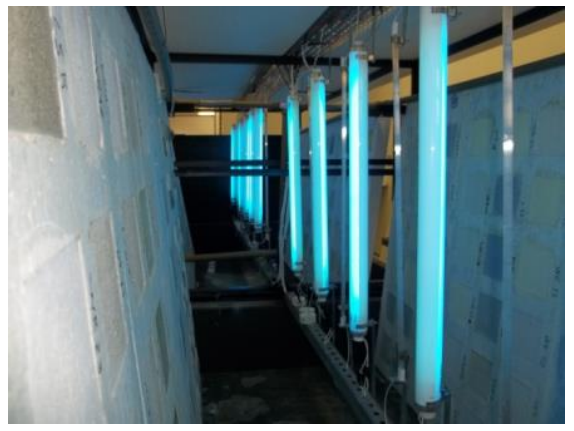

(c) Radiação ultravioleta

Os corpos de prova utilizados foram moldados a partir de formas confeccionadas com placas de poliestireno expandido (EPS), com espessuras de $2,0 \mathrm{~cm} \mathrm{e} \mathrm{4,0} \mathrm{cm,} \mathrm{sendo} \mathrm{na} \mathrm{placa} \mathrm{de} \mathrm{menor}$ espessura efetuados cortes de $10 \mathrm{~cm} \mathrm{x} 10 \mathrm{~cm} \mathrm{e}$ extraídos os quadrados que limitaram as laterais das formas na profundidade de $2,0 \mathrm{~cm}$ quando colada na placa de maior espessura, a qual determinou o fundo. Em cada placa foi possível produzir dezoito posições para moldagem e suporte dos corpos de prova, conforme ilustrado pela Figura 3.

Foi definida como matriz cimentícia para confecção dos corpos de prova uma argamassa mista de cimento : cal: areia na proporção de 1:1:9, em unidades de massa seca, de acordo com o traço apresentado na Tabela 1, com caracterização dos materiais apresentados conforme a Tabela 2 e distribuição granulométrica conforme a Figura 4, com uma relação de água e materiais secos de $21 \%$.

Ainda em relação à Tabela 1 , faz-se necessário esclarecer que MS(1) representa a massa resultante de todo o material seco utilizado na composição do traço, ou seja, a soma das massas de cimento, cal e areia. VS(2) representa o volume específico resultante de todo o material seco utilizado na composição do traço, ou seja, a soma das massas de cimento, cal e areia, onde volume específico é definido pelo volume ocupado pelos sólidos, desconsiderando-se os vazios da mistura e a porosidade característica de cada material. MU(3)

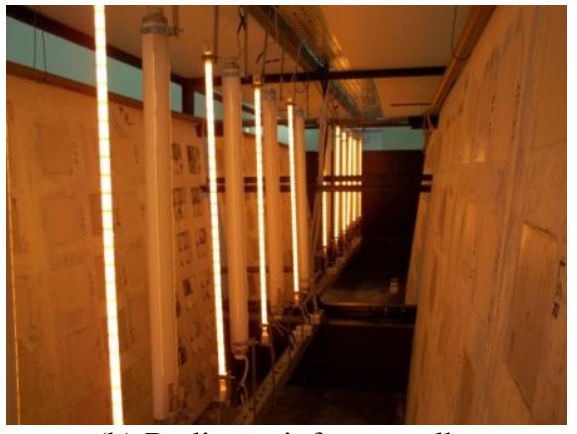

(b) Radiação infravermelha

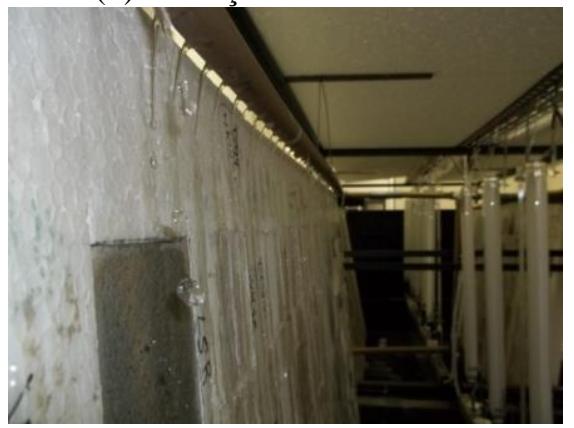

(d) Molhagem dos corpos de prova

representa a relação entre a massa resultante de todo o material seco utilizado na composição do traço, ou seja, a soma das massas de cimento, cal e areia e determinado volume ocupado por essa mistura, considerando-se os vazios. ME(4) representa a relação entre a massa resultante de todo o material seco utilizado na composição do traço, ou seja, a soma das massas de cimento, cal e areia e determinado volume ocupado por essa mistura, desconsiderando-se os vazios e que $\rho_{\mathrm{t}} \%(5)$ representa a relação entre a MU e a ME do mesmo material ou composição, subtraída de $100 \%$ do volume ocupado.

Os tratamentos superficiais foram aplicados 60 dias após a moldagem dos corpos de prova de argamassa, com o objetivo de minimizar os impactos dos processos de carbonatação, sendo que nos primeiros 30 dias todos permaneceram em câmara úmida e nos 30 dias restantes foram expostos em ambiente ventilado dentro do laboratório. Todos os corpos de prova foram moldados no mesmo dia, através da conformação de três traços de igual característica. Os tratamentos se deram por meio de pintura superficial com o auxílio de um pincel em duas demãos, cada uma aplicada em uma direção ou aplicação cruzada, com intervalo de $5 \mathrm{~min}$ entre cada demão.

Antes e depois das aplicações o conjunto pincel e recipiente foram pesados, permitindo calcular o consumo do tratamento total empregado e do dióxido de titânio. 
Foram avaliadas as seguintes condições nas superfícies:

(a) referência (sem tratamento);

(b) aplicação de dispersão aquosa de $\mathrm{TiO}_{2}$ nas concentrações de $1 \%$ e $5 \%$ (DISP $_{1}$ e DISP $_{2}$ respectivamente), em massa;

(c) aplicação do hidrofugante à base de silicone do tipo octiltrietoxissilano produzido pela empresa Dow Corning Corporation $\left(\mathrm{WR}_{10}\right)$; e (d) aplicação da mistura de $\mathrm{TiO}_{2}$ e hidrofugante nas concentrações de $1 \%$ e $5 \%\left(\mathrm{WR}_{11}\right.$ e $\mathrm{WR}_{12}$ respectivamente), em massa, como pode ser observado na Tabela 3.

O hidrofugante foi diluído em uma concentração de $10 \%$ em relação à quantidade de água, em massa, para todos os casos.

Figura 3 - Ilustração da placa produzida de EPS para moldagem e suporte dos corpos de prova. À esquerda vistas e corte superior, e à direita detalhe ampliado com as dimensões (sem escala)

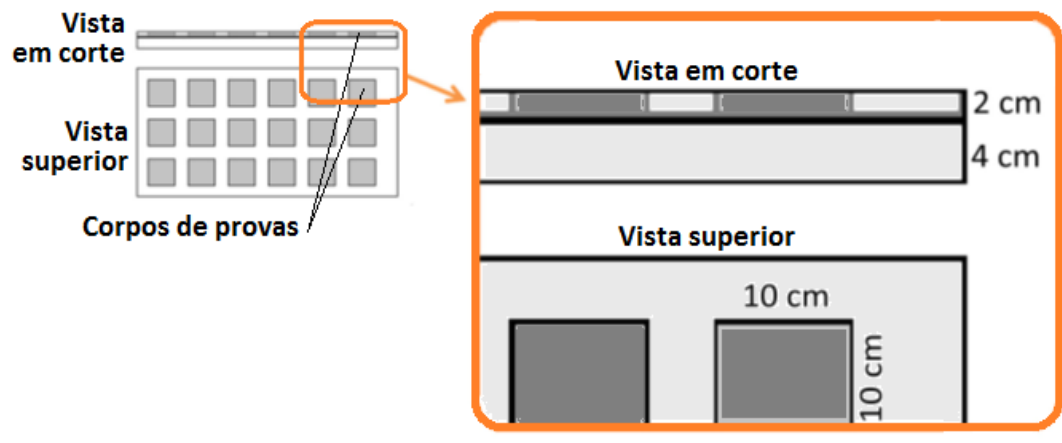

Tabela 1 - Traço característico empregado para a conformação da argamassa mista

\begin{tabular}{|c|c|c|c|c|c|c|c|c|}
\hline & MU & ME & $\rho_{t} \%$ & $\underset{\text { (g) }}{\text { CP II } 32 ~ E}$ & $\begin{array}{c}\text { CH I } \\
\text { (g) }\end{array}$ & $\begin{array}{c}\text { Areia } \\
\text { Média (g) }\end{array}$ \\
\hline & & & $\begin{array}{c}\text { MS/V rec } \\
\text { (g/ml) }\end{array}$ & $\begin{array}{c}\text { MS/VS } \\
(\mathrm{g} / \mathrm{ml})\end{array}$ & $\begin{array}{c}1-(\text { MU/ME) } \\
(\%)\end{array}$ & 1,00 & 1,00 & 9,00 \\
\hline Traço & V rec $(\mathrm{ml})$ & 3000,50 & \multirow{3}{*}{1,39} & \multirow{3}{*}{2,65} & \multirow{3}{*}{47,34} & 272,77 & 272,77 & $2.454,95$ \\
\hline $1: 1: 9$ & MS (g) & $4.182,97$ & & & & 313,69 & 211,40 & $3.657,88$ \\
\hline$(\mathrm{g})$ & VS (ml) & $1.579,96$ & & & & 101,19 & 96,09 & $1,382,68$ \\
\hline
\end{tabular}

Nota: Legenda:

CP II $32 \mathrm{E}$ = Cimento Portland composto com adição de ;escória de alto forno e resistência à compressão média de $32 \mathrm{MPa}$ (Megapascal) no $28^{\circ}$ dia de cura

$\mathrm{CH}$ I = Cal hidratada do tipo I;

$\mathrm{V}$ rec = volume do recipiente;

$M S=$ massa total da mistura dos sólidos ${ }^{1}$;

VS = volume total da mistura dos sólidos ${ }^{2}$;

$M U$ = massa unitária total da mistura dos sólidos ${ }^{3}$;

$\mathrm{ME}=$ massa específica total da mistura dos sólidos ${ }^{4}$;

$\rho_{\mathrm{t}} \%=$ porosidade total da mistura dos sólidos ${ }^{5}$;

$\mathrm{ml}=$ mililitros; $\mathrm{e}$

$\mathrm{g}=$ gramas.

Tabela 2 - Caracterização dos materiais ligantes e agregado utilizados no traço

\begin{tabular}{c|c|c|c}
\hline Elementos & MU $(\mathbf{g} / \mathbf{m l})$ & ME $(\mathbf{g} / \mathbf{m l})$ & $\boldsymbol{\rho}(\%)$ \\
\hline CP II 32 E & 1,150 & 3,100 & 62,90 \\
CH I & 0,775 & 2,200 & 64,77 \\
Areia Média & 1,490 & 2,650 & 43,68 \\
\hline
\end{tabular}

Nota: Legenda:

CP II $32 \mathrm{E}=$ Cimento Portland composto com adição de escória de alto forno e resistência à compressão média de $32 \mathrm{MPa}$ (Megapascal) no $28^{\circ}$ dia de cura;

$\mathrm{CH}$ I = Cal hidratada do tipo I;

$\mathrm{MU}=$ massa unitária do sólido;

$M E$ = massa específica do sólido; $\mathrm{e}$

$\rho \%=$ porosidade . 
Figura 4 - Distribuição granulométrica dos materiais utilizados no traço

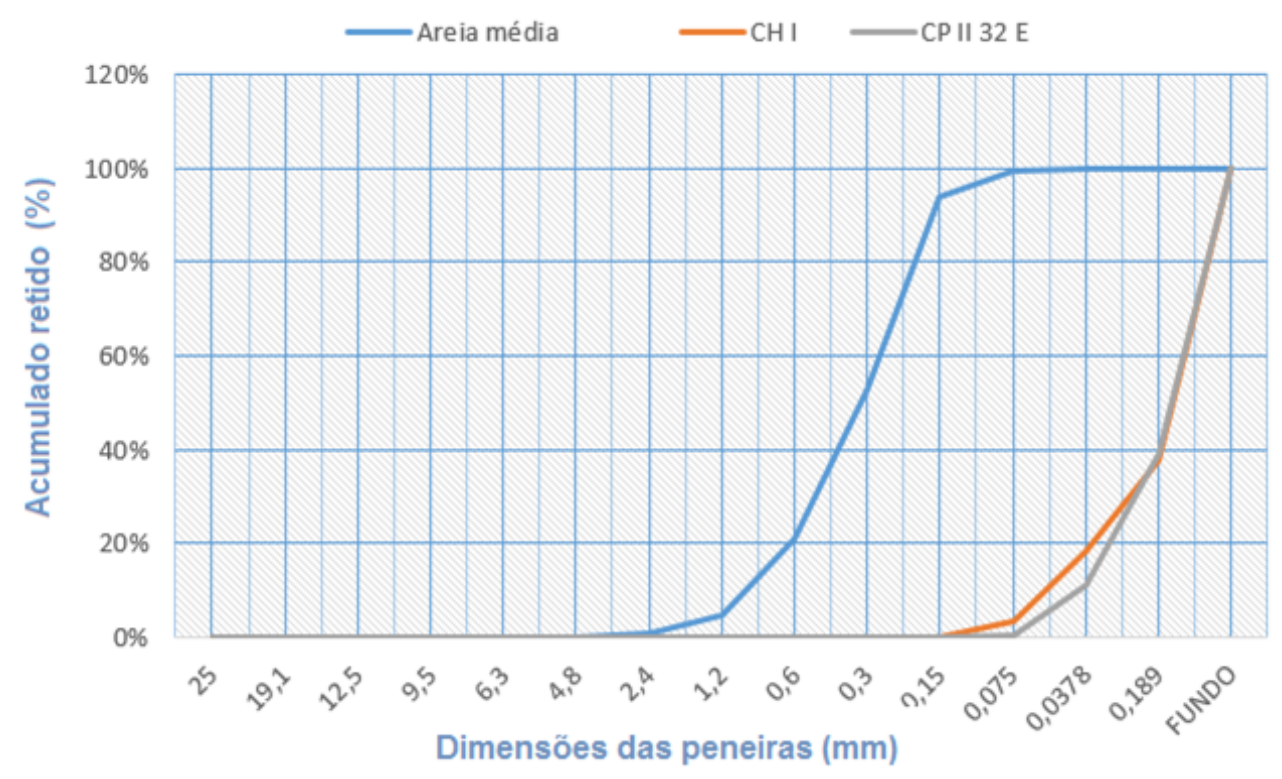

Tabela 3 - Modelagem de composição na determinação do pós-tratamento

\begin{tabular}{c|c|c|c|c|c}
\hline & \multicolumn{5}{|c}{ COMPOSTOS } \\
\cline { 2 - 6 } & $\mathbf{W R}_{\mathbf{1 0}}$ & $\mathbf{W R}_{\mathbf{1 1}}$ & $\mathbf{W R}_{\mathbf{1 2}}$ & $\mathbf{D I S P}_{\mathbf{1}}$ & $\mathbf{D I S P}_{\mathbf{2}}$ \\
\hline Teores de $\mathrm{TiO}_{2}$ & $0 \%$ & $1 \%$ & $5 \%$ & $1 \%$ & $5 \%$ \\
\hline
\end{tabular}

O semicondutor utilizado foi o dióxido de titânio da marca Millenium, que, segundo o fabricante, é formado por grãos de anatásio com dimensões inferiores a $40 \mathrm{~nm}$.

Como base para comparação dos resultados também foi utilizado o produto comercial Lasure (LSR), da marca Guard Industry (http://www.guardindustry.com), que, segundo o fabricante, possui propriedades fotocatalíticas.

As propriedades fotocatalíticas foram avaliadas pelas cinéticas de redução das intensidades das manchas dos corpos de prova geradas com azul de metileno disperso em álcool etílico $\left(92,8{ }^{\circ} \mathrm{GL}\right)$ e em água deionizada, na concentração de $1 \%$ em relação aos líquidos, ao longo dos 200 ciclos de envelhecimento. Para tal, todos os corpos de prova foram fotografados a cada 25 ciclos, e as cores comparadas em relação a duas escalas de cores previamente definidas, apresentadas na Figura 5. Os dados de comparação entre as escalas de cores e as imagens dos corpos de prova foram obtidos a partir de 20 diferentes observadores, solicitados a participar do programa experimental. Tais observadores receberam os mesmos catálogos com as imagens dos corpos de prova e as mesmas paletas com as escalas de cores, gerando então uma coleção de dados, tratados conforme a Equação (1), possibilitando a geração dos gráficos das degradações das manchas de azul de metileno nas superfícies por meio de cálculo simplificado de percentual de decaimento da intensidade da mancha. Tal procedimento se fez necessário porque a intensidade da mancha inicial variou em função do tipo de tratamento aplicado e do meio que o azul de metileno foi disperso.

Tem-se:

$M \%=\frac{M t \%-M o \%}{M t \%}$

Eq. 1

Onde:

M\%: taxa de manchamento final;

Mt\%: intensidade inicial da mancha; e

Mo\%: intensidade da mancha observada conforme escalas de cores.

Foram submetidas ao envelhecimento artificial 16 placas com 18 corpos de prova cada uma, totalizando 288 corpos de prova distribuídos aleatoriamente, sendo 42 peças de referência (sem tratamento) e 41 peças para cada tipo de variável de pós-tratamento, conforme apresentado na tabela 3, e 41 peças do produto comercial (LSR). As dispersões de azul de metileno foram aplicadas em $50 \%$ dos corpos de prova, sendo mantida a outra metade igualmente tratada e exposta às agressões preestabelecidas pelo programa de envelhecimento artificial. Dessa forma, foi possível manter 
simultaneamente todos os corpos de prova sob as mesmas condições de degradação.

Após 50 ciclos de envelhecimento foram realizadas aplicações dos agentes manchantes nos corpos de prova sem o manchamento inicial, com objetivo de avaliar os desempenhos do póstratamento após programa experimental, o que permitiu observar as diferenças nos comportamentos entre as placas manchadas inicialmente e as placas manchadas após sofrerem envelhecimento por 50 ciclos. Considerou-se, então, que para as placas manchadas após 50 ciclos iniciava-se uma nova contagem de ciclos, repetindo-se assim o mesmo procedimento de registro e coleta de dados até 200 ciclos.

Com isso, foram igualmente avaliados dois grupos de corpos de prova por 200 ciclos cada, porém defasados de 50 ciclos. Metade recebeu a aplicação das dispersões do azul de metileno no estágio inicial (sem envelhecimento), e a outra metade recebeu a aplicação do azul de metileno (com envelhecimento) após 50 ciclos, permitindo a comparação dos resultados.

Além disso, foram realizadas avaliações microestruturais por meio de microscopia eletrônica de varredura (MEV), com um equipamento modelo Quanta 600 FEG, com espectrômetro de dispersão de energia (EDS) da Bruker e com software para microanálise Spirit, também da Bruker.

Todas as avaliações foram realizadas sobre partes extraídas dos corpos de prova das diversas amostras com dimensões de $1,0 \mathrm{~cm} \times 1,0 \mathrm{~cm} \times 0,5$ $\mathrm{cm}$, sendo em cada uma realizadas cinco leituras do EDS em diferentes pontos de cada amostra.

Figura 5 - Escalas de cores utilizadas para avaliação da intensidade da mancha com azul de metileno ao longo do programa de envelhecimento artificial

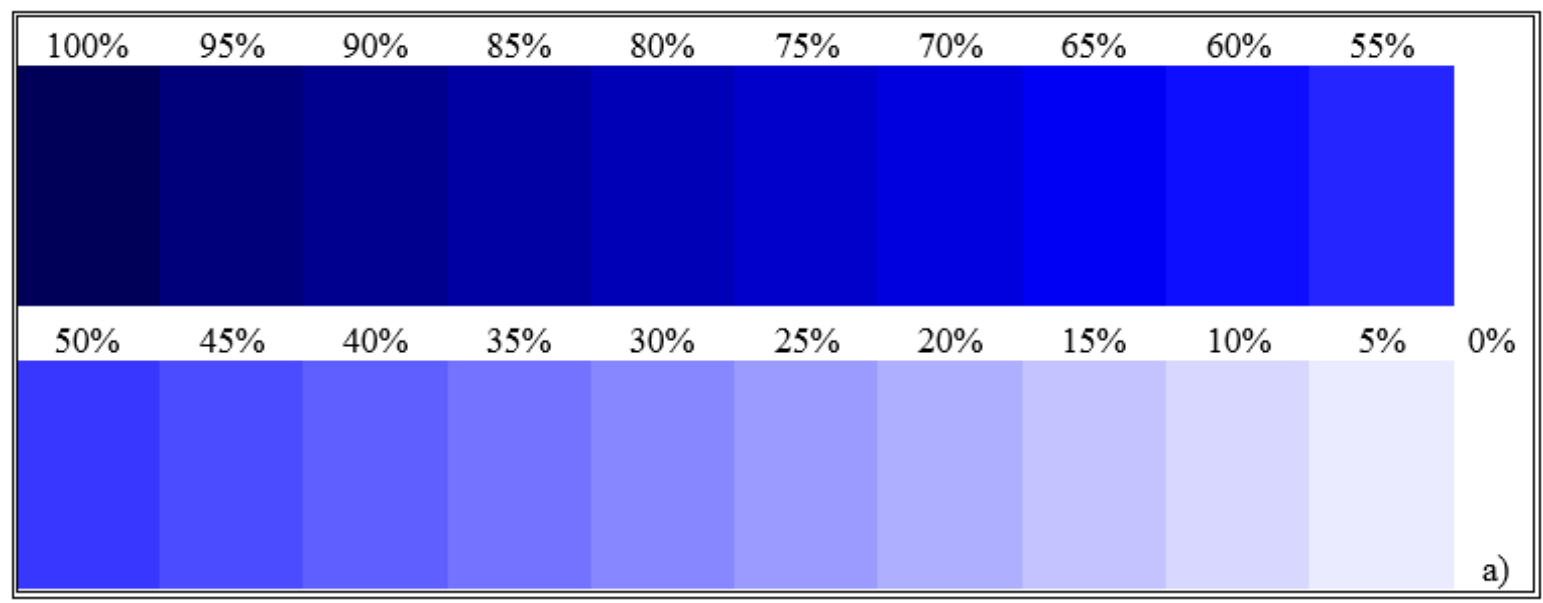

(a) Dispersão de azul de metileno em água

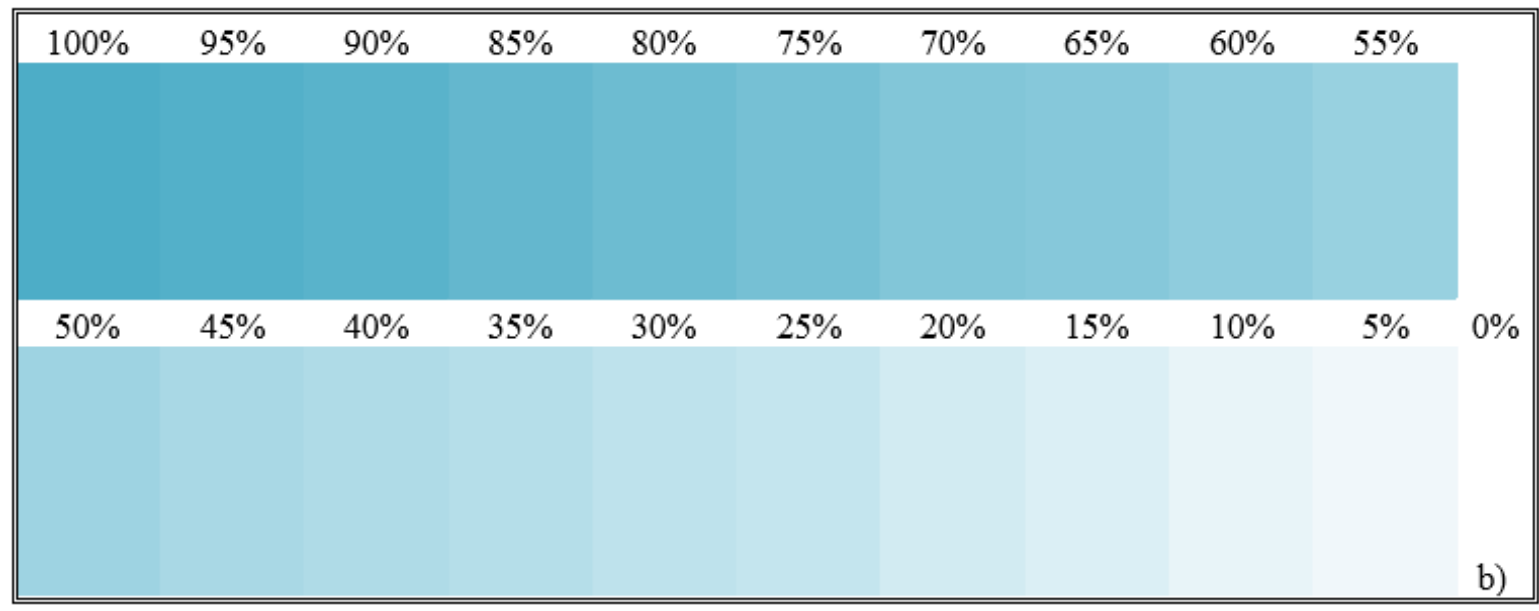

(b) Dispersão de azul de metileno em álcool 


\section{Resultados e discussões}

Na Figura 6 são apresentados os resultados das médias dos consumos dos tratamentos superficiais e do dióxido de titânio. Os tratamentos com suspensão aquosa do $\mathrm{TiO}_{2}$ tiveram consumo maior quando comparados com os combinados ao hidrofugante, bem como com o produto comercial. Em todos os casos o consumo do semicondutor foi inferior a $5 \mathrm{~g} / \mathrm{m}^{2}$ para as concentrações de $1 \%$ e em média de $22 \mathrm{~g} / \mathrm{m}^{2}$ para a concentração de $5 \%$, tanto para as dispersões quanto para as combinações com o silicone.

Conforme representado pela Figura 5, nota-se que há diferença entre os consumos dos pares DISP ${ }_{1}$ $\mathrm{WR}_{11}$ e $\mathrm{DISP}_{2}-\mathrm{WR}_{12}$, cujas suspensões 1 e 2 (DISP), apesar de terem sido compostas com os mesmos teores de $\mathrm{TiO}_{2}$, apresentam consumo superior quando comparadas às diluições de silicone (WR). Isso pode ser atribuído ao procedimento de aplicação dos tratamentos. As dispersões são apenas suspensões aquosas; quando aplicada a primeira demão (conforme já mencionado em Materiais e Métodos), essa não impermeabiliza a superfície, e a segunda demão também sofre absorção pela superfície porosa, retendo maior quantidade de material sólido. No caso das superfícies que têm como tratamento as diluições de silicone, ao receberem a segunda demão, a primeira já foi parcialmente absorvida e sofreu secagem sob o efeito da exposição ao ar, permitindo que a aplicação da segunda demão seja mais suave e com menor retenção de material sólido, o $\mathrm{TiO}_{2}$.

Apesar de o dióxido de titânio possuir alto valor agregado e seu custo no Brasil ser de aproximadamente US\$ 5.000,00/t (1US\$=3R\$), esse consumo unitário representou um custo inferior a $\mathrm{R} \$ 0,30 / \mathrm{m}^{2}$ para a maior concentração utilizada nesse programa experimental, quando os resultados são considerados mais interessantes quanto menor for a quantidade do semicondutor, sem comprometimento do desempenho fotocatalítico. No caso em análise, considera-se o resultado para o custo por metro quadrado favorável à distribuição comercial, haja vista que mesmo para aplicação em áreas extensas o valor total final não representaria impacto significativo no montante da construção ou processo fabril.

Nas Figuras 7 e 8 estão apresentados os resultados da cinética de redução da intensidade das manchas com azul de metileno em placas novas. Para os dois tipos de dispersões do azul de metileno, considerando as devidas diferenças entre as intensidades iniciais das manchas (em água e em álcool), observa-se comportamento semelhante ao longo do processo de envelhecimento artificial. Nas Figuras 9 e 10 observam-se as aplicações de azul de metileno nos corpos de prova em quadrantes, em que o quarto inferior esquerdo representa o manchamento obtido a partir da dispersão em água e o quarto superior direito representa o manchamento obtido a partir da dispersão em álcool, onde é possível observar a diferença na intensidade dos manchamentos.

Os corpos de prova que não receberam tratamento superficial apresentaram uma degradação de $25 \%$ do manchamento inicial, enquanto naqueles tratados apenas com o hidrofugante à base de silicone a degradação ocorreu principalmente pela lixiviação das partículas de azul de metileno devido à menor adesão desse agente manchante. Não se notou influência do material lixiviado em relação à contaminação e manchamento dos corpos de prova, independentemente da posição ocupada nas placas de ensaio.

Figura 6 - Consumos médios dos tratamentos (a) e do dióxido de titânio nos corpos de prova (b), sendo os desvios padrão indicados dentro do quadro vermelho, em gramas

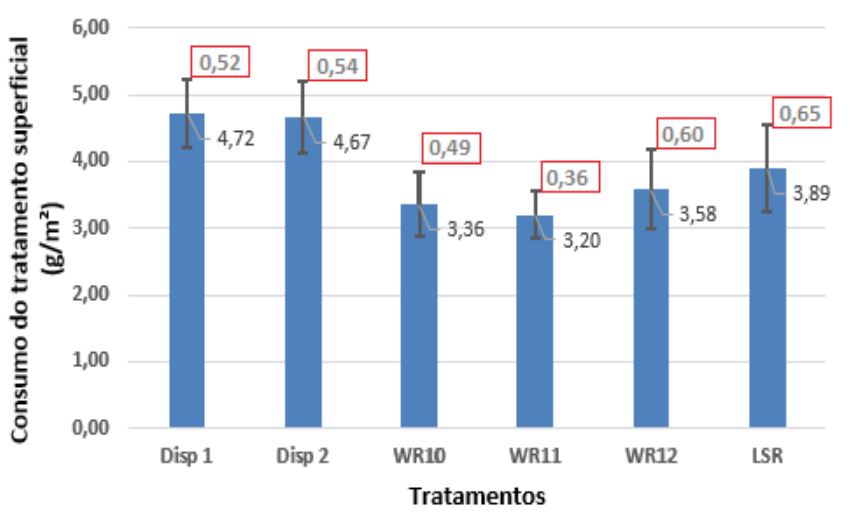

(a)

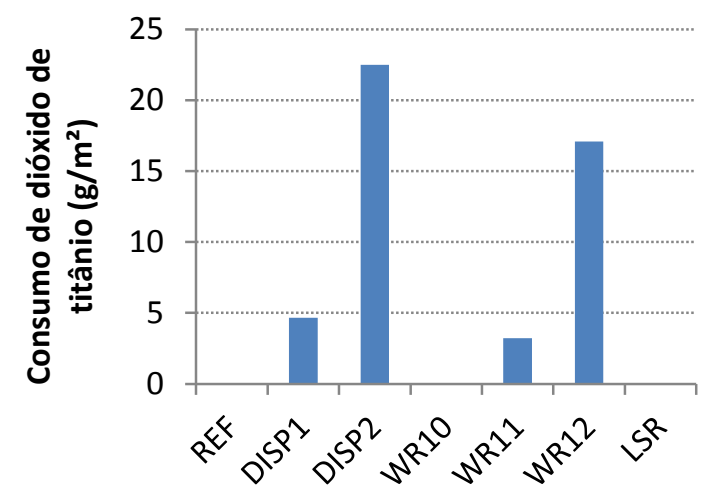

(b) 
Figura 7 - Resultados da cinética de redução da intensidade das manchas em substratos tratados com suspensões aquosas de dióxido de titânio e com o produto comercial
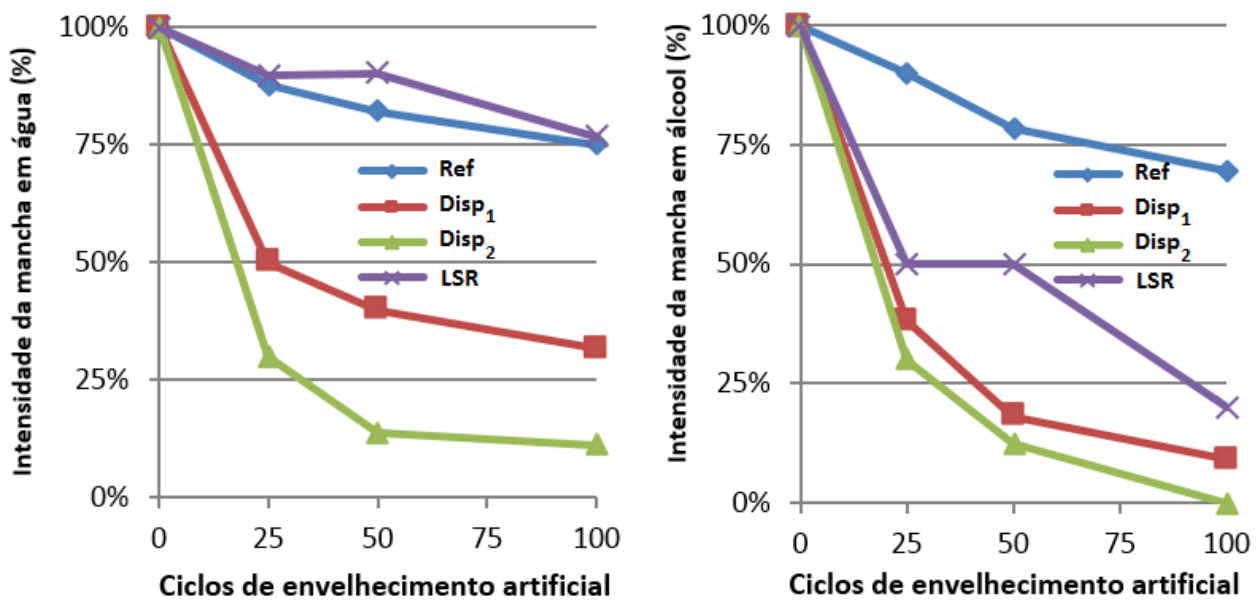

Figura 8 - Resultados da cinética de redução da intensidade das manchas em substratos tratados com a união de dióxido de titânio e um hidrofugante à base de silicone
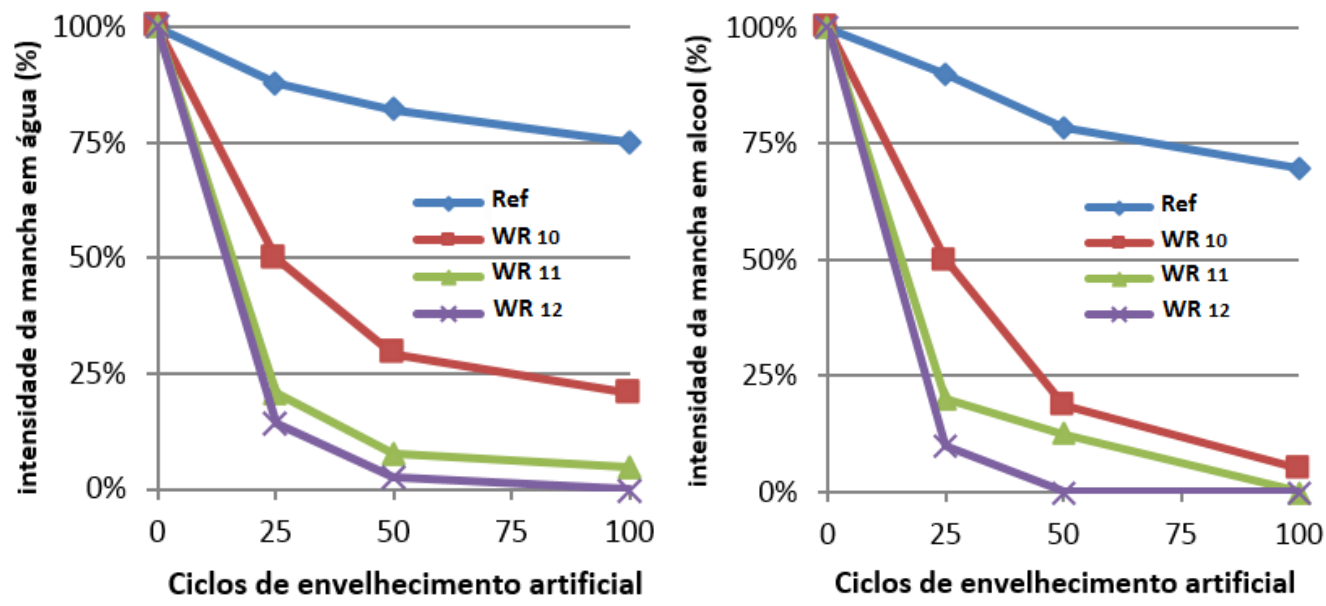
Figura 9 - Ilustração da variação de intensidade da mancha ao longo dos ciclos de envelhecimento artificial em placas novas de corpos de prova tratados com suspensões de $\mathrm{TiO}_{2}$

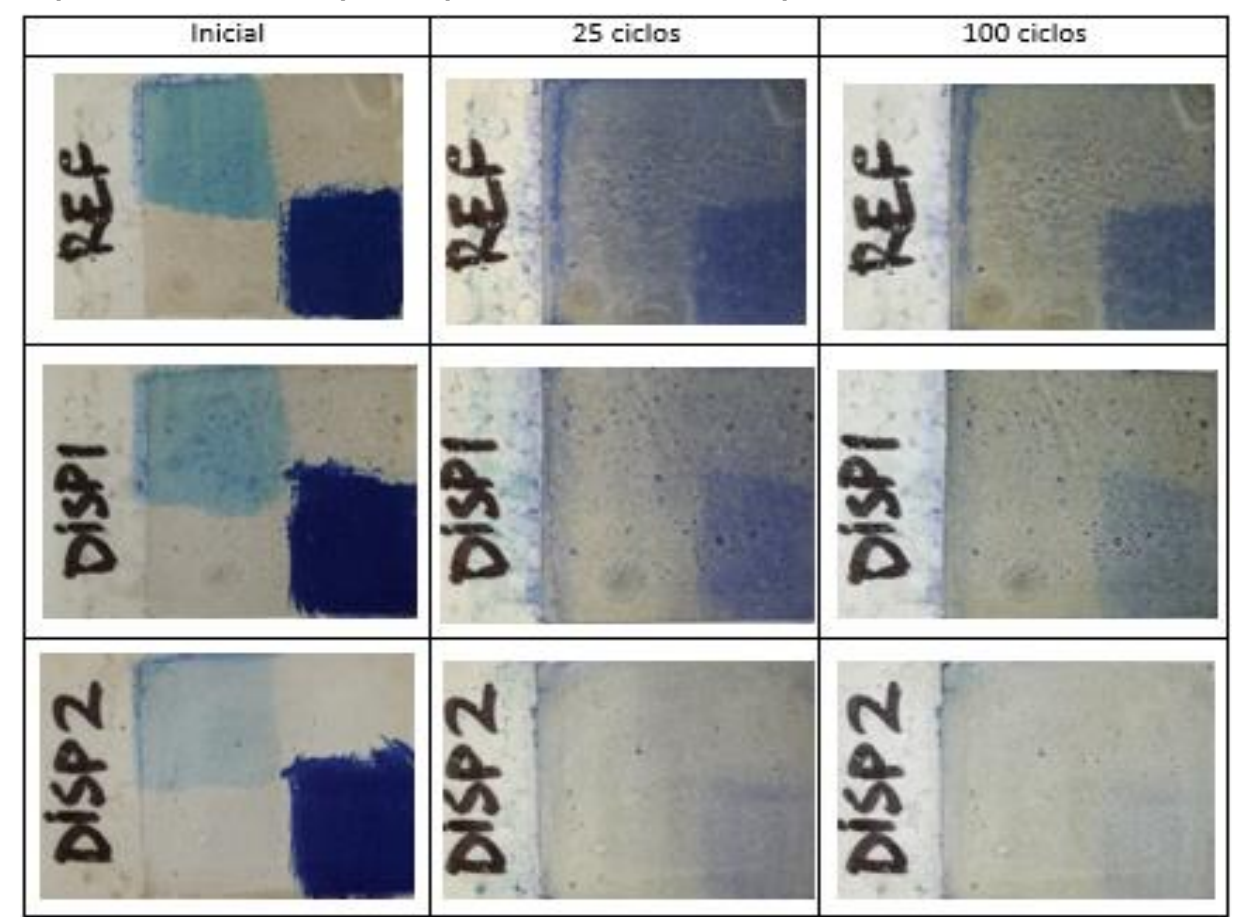

Figura 10 - Ilustração da variação de intensidade da mancha ao longo dos ciclos de envelhecimento artificial em placas novas de corpos de prova tratados com hidrofugante e $\mathrm{TiO}_{2}$

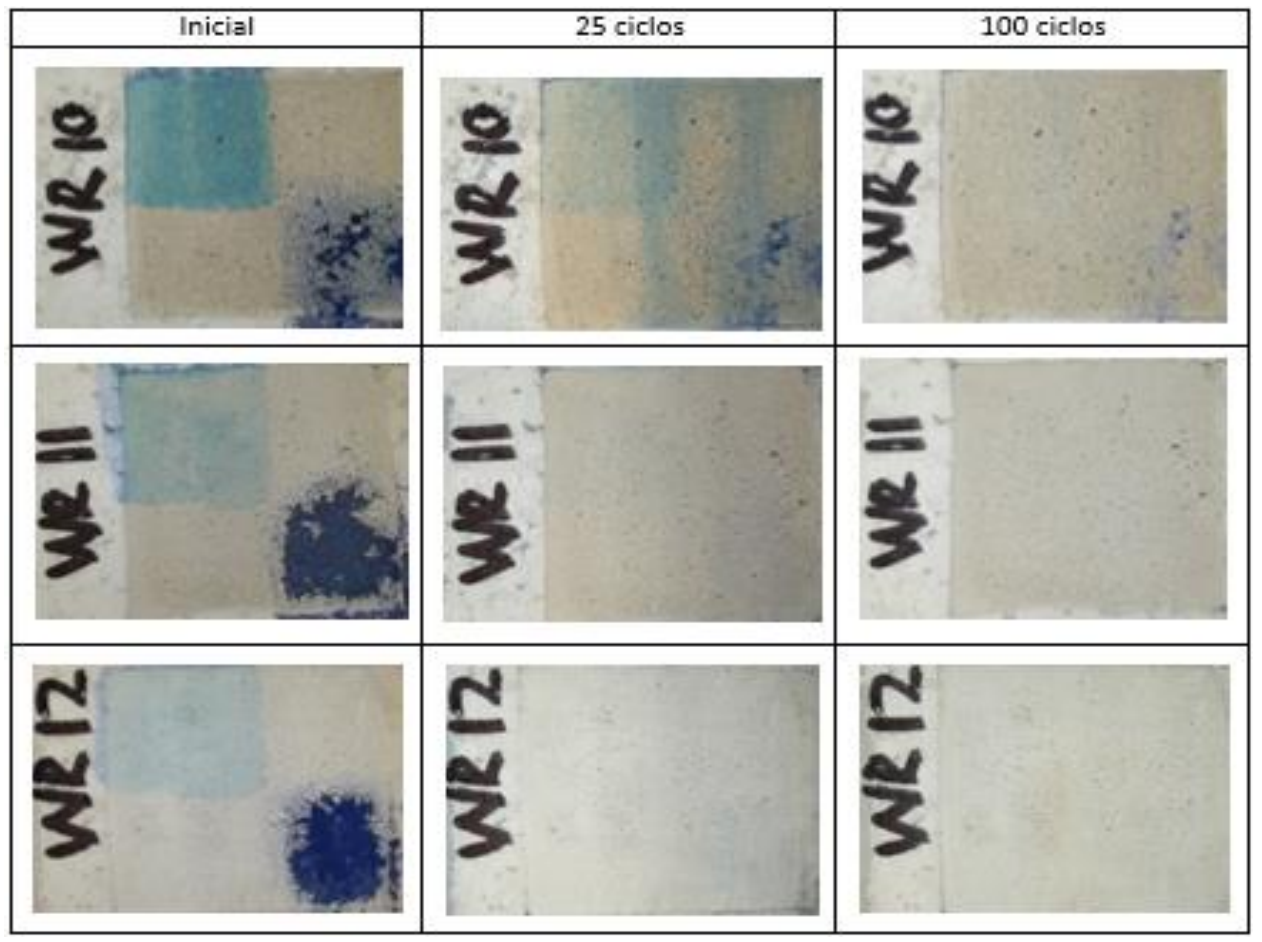

Todos os corpos de prova que receberam tratamentos com dióxido de titânio apresentaram uma cinética de redução da intensidade da mancha mais acentuada, sendo tão intensa quanto maior a concentração de $\mathrm{TiO}_{2}$. Esse comportamento pode ser atribuído à fotoativação do dióxido de titânio pela radiação UV e à degradação do azul de metileno (MARANHÃO, 2009).

316 Garcia Junior, G. C.; Botter, E. de A.; Maranhão, F. L. 
Nos corpos de prova em que se uniram o hidrofugante e o $\mathrm{TiO}_{2}$ as duas concentrações do semicondutor utilizadas apresentaram comportamento semelhante, podendo, nesse caso, ser consequência de uma sobreposição de algumas partículas pelos radicais hidrofóbicos que possuem menor tensão superficial e funcionam como uma barreira à fotoativação pela radiação UV.

Em todos os casos, após 100 ciclos praticamente não se conseguem observar manchas nas superfícies dos corpos de prova tratados com os compostos que receberam a adição de $\mathrm{TiO}_{2}$ e não se observam alterações significativas nos corpos de prova de referência e do produto comercial, apresentando até os 200 ciclos finais um comportamento semelhante, o que não justifica a apresentação desses resultados no tratamento de dados.

Um ponto que merece ser destacado é o fato de que todos os corpos de prova que receberam tratamentos com 5\% de dióxido de titânio apresentaram amarelamento superficial ao longo dos testes laboratoriais. Não se tem uma explicação precisa para tal fenômeno, mas uma hipótese a ser considerada é que seja pela degradação de algum material orgânico depositado na superfície das partículas de $\mathrm{TiO}_{2}$. Nos experimentos de Hao (2004) foi reportado comportamento semelhante.

Os corpos de prova tratados com o produto comercial avaliado na pesquisa apresentaram baixa atividade fotocatalítica e uma cinética de redução dos manchamentos mais semelhante aos corpos de prova sem tratamento superficial.

Comparando os resultados obtidos nas placas novas (como apresentado anteriormente nas Figuras 7 e 8) e nas placas já envelhecidas com 50 ciclos (Figura 11), constatam-se algumas diferenças importantes. Na medida em que as placas já estão envelhecidas, a cinética de redução dos manchamentos diminui em todos os casos, sendo nos tratamentos com dióxido de titânio essas diferenças menores, confirmando que os processos fotocatalíticos continuam acontecendo (GUO et al., 2013).

Essa queda de desempenho é evidente nos tratamentos em que não se utilizou o hidrofugante como agente de fixação e, possivelmente, está relacionada à lixiviação das partículas de $\mathrm{TiO}_{2}$ como consequência da baixa aderência (DIAMANTI; ORMELLESE; PEDEFERRI, 2008) ou mesmo pela deposição de produtos de hidratação sobre as partículas do semicondutor, criando uma barreira à radiação UV. Por outro lado, nos tratamentos em que se uniu o hidrofugante à base de silicone e o dióxido de titânio, essas diferenças foram menos significativas (Figura 11).

Como outra forma de comprovar o que o estudo qualitativo por diferenças de intensidades de cores forneceu foram realizadas as análises com MEV, o que permitiu concluir que o uso do EDS é uma eficiente ferramenta semiquantitativa para avaliar o pós-tratamento com dióxido de titânio, pois conseguem diferenciar as concentrações aplicadas. Além disso, os métodos referidos permitem identificar a queda na concentração de $\mathrm{TiO}_{2}$ ao longo dos ciclos de envelhecimento artificial (Figura 12) e que, quando não foi usado um agente de fixação, a concentração de $\mathrm{TiO}_{2}$ na superfície dos corpos de prova foi reduzida em cerca de $90 \%$, o que é significativamente superior aos $20 \%$ encontrados naqueles em que se usou o hidrofugante à base de silicone.

\section{Figura 11 - Resultados da cinética de redução da intensidade das manchas em substratos de argamassa previamente envelhecidos com 50 ciclos}
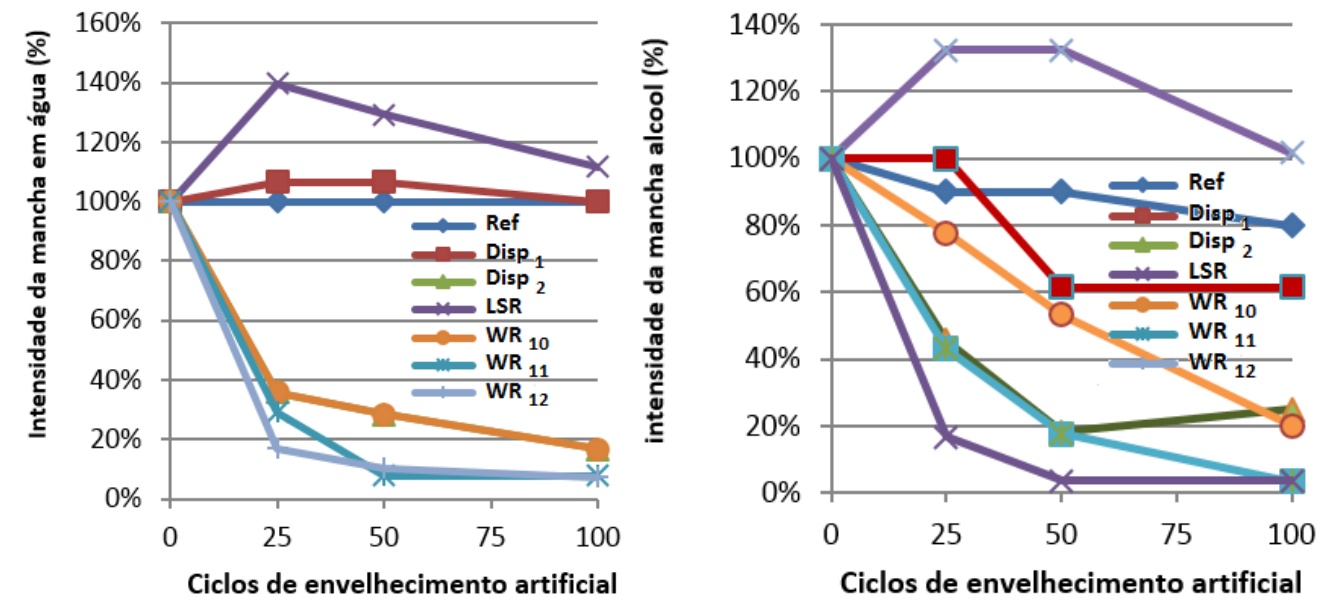
Figura 12 - Variação da concentração de $\mathrm{TiO}_{2}$ inicial e após 200 ciclos de envelhecimento artificial (linha verde)

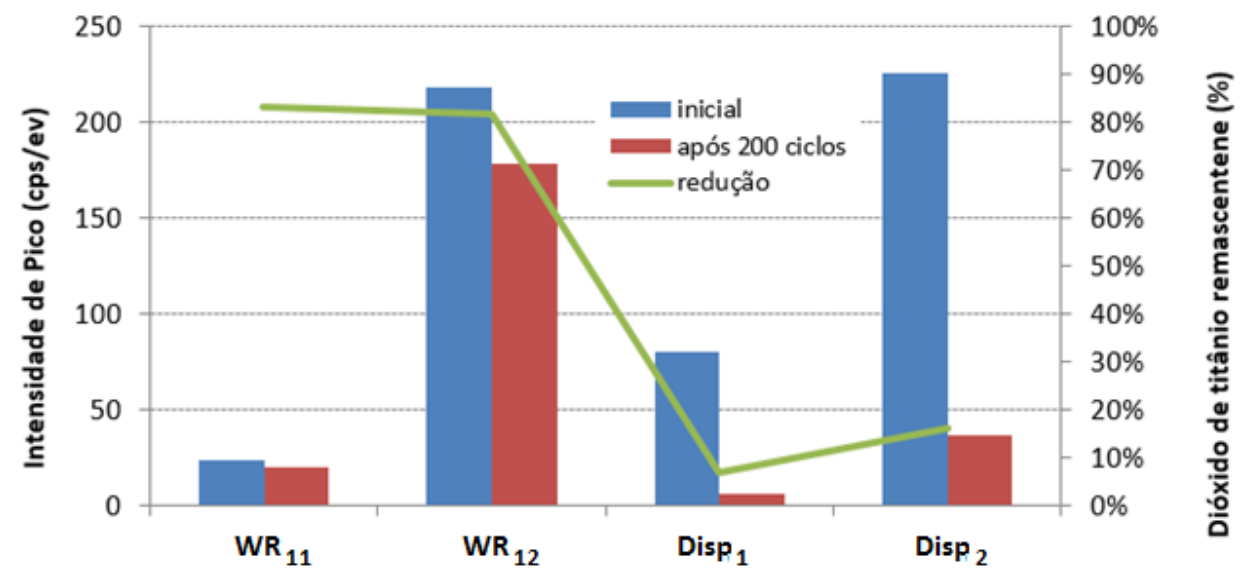

\section{Conclusões}

Os métodos indicadores escolhidos para a quantificação e verificação da presença da atividade fotocatalítica mostraram-se apropriados, pois permitiram acompanhar as mudanças nos comportamentos dos corpos de prova durante o avanço dos ciclos de envelhecimento artificial através da observação das diferenças das cinéticas de degradação das manchas, sendo mantidas as propriedades hidrofóbicas atribuídas à combinação dos compostos com o hidrofugante, mesmo quando as variáveis de pós-tratamento foram submetidas a radiação ultravioleta.

O programa de envelhecimento artificial mostrouse adequado para avaliar os processos fotocatalíticos, aplicados como pós-tratamentos em argamassas mistas, proporcionando diferenciar a cinética de redução dos manchamentos com azul de metileno e diferenciar as placas novas das envelhecidas.

Com base na observação e comparação dos resultados, os corpos de prova pós-tratados com os silicones como agente de fixação do semicondutor apresentaram desempenho superior aos corpos de prova pós-tratados com as suspensões aquosas e com o produto comercial. Após 50 ciclos de envelhecimento artificial, todos os corpos de prova adicionados do semicondutor no pós-tratamento tiveram comportamento semelhante, mesmo havendo sido observado que as suspensões com concentração superior do $\mathrm{TiO}_{2}(5 \%)$ apresentaram decaimento inicial maior para a redução das manchas, porém com amarelamento da superfície.

Para as amostras previamente envelhecidas, manchadas e submetidas novamente ao envelhecimento artificial, tem-se o mesmo padrão na cinética de redução das manchas, em proporções próximas às observadas inicialmente, o que demonstra a continuidade da atividade fotocatalítica e, portanto, a fixação do $\mathrm{TiO}_{2}$, o que permite afirmar que o processo fotocatalítico se mostrou resistente ao programa de ensaios, enquanto nos tratamentos em que não se utilizou um agente ligante mensurou-se queda na concentração de partículas de $\mathrm{TiO}_{2}$ e de desempenho do sistema, quando comparadas às cinéticas das placas novas e envelhecidas. Pelo exposto, conclui-se que os agentes de fixação são importantes para garantir a durabilidade dos tratamentos e que produtos com características inorgânicas mostram-se adequados.

Dessa forma, admite-se que o composto com melhor resultado foi o $\mathrm{WR}_{11}\left(\mathrm{WR}_{1}+1 \% \mathrm{TiO}_{2}\right)$, o qual apresentou desempenho satisfatório diante da proposta de constituir e avaliar um produto para pós-tratamento que atribuísse características autolimpantes às superfícies de matriz cimentícia na forma de argamassa para revestimento externo, com o emprego de um semicondutor associado a um silicone, possuindo apenas como força motriz a incidência da radiação ultravioleta. Não houve alteração de tonalidade da superfície na aplicação, tampouco ao longo do processo de ensaios, sendo ainda resistente ao programa de envelhecimento artificial.

\section{Referências}

BONETTA, S. et al. Evaluation of the Antimicrobial Activity of Surface Coated with $\mathrm{TiO}_{2}$. In: INTERNATIONAL RILEM SYMPOSIUM ON PHOTACATALYTIS, ENVIRONMNET AND CONSTRUCTION MATERIALS, Italy, 2007. Proceedings... Italy, 2007. 
CASSAR, L. Photocatalysis of Cimentitious Materials: clean building and clean air. MRS Bulletin, p. 1-4, may 2004.

DIAMANTI, M. V.; ORMELLESE, M.; PEDEFERRI, M. P. Characterization of Photocatalytic and Superhydrophilic Properties of Mortars. Cement and Concrete Research, v. 38, n. 11, p. 1349-1353, 2008.

DIAMANTI, M.V. et al. Mutual Interactions Between Carbonation and Titanium Dioxide Photoactivity in Concrete. Building and Environment, v. 62, p. 174-181, abr. 2013.

FOLLI, A. et al. Rhodamine B Discolouration on $\mathrm{TiO}_{2}$ in the Cement Environment: a look at fundamental aspects of the self-cleaning effect in concretes. Journal of Advanced Oxidation Technologies, v. 12, n. 1, 2009.

FOLli, A. $\mathrm{TiO}_{2}$ Photocatalysis in Portland Cement Systems: fundamentals of self cleaning effect and air pollution mitigation. Aberdeen, 2010. 156f. Thesis (Doctor of Philosophy) Department of Chemistry, University of Aberdeen, Aberdeen, 2010.

GUO, M. et al. Nano-TiO 2 -Based Architectural Mortar for NO Removal and Bacteria Inactivation: influence of coating and weathering conditions. Cement \& Concrete Composites, v. 36, p. 101108, 2013.

GUROL, M. Photo-Catalytic Construction Materials and Reduction in Air Polluants. Report presented to California Senate, 2006. Disponível em:

<http://www.csus.edu/calst/government_affairs/re ports/PHOTO-CATALYTIC.pdf>. Acesso em: 23 jan. 2008.

HAO, C. Photocatalytic Performance of Titanium Dioxide in Coating Formulation. Queensland, 2004. 66 f. Thesis (Graduation) School of Engineering Faculty of Engineering, Physical Sciences and Architecture, UNIVERSITY OF QUEENSLAND, 2004.

KURTH, J. Mitigation Biofilm Growth Through the Modification of Concrete Design and Practice. 160 f. 2008. Dissertação (Mestrado em Engenharia Civil) - Georgia Institute of Technology, Georgia, 2008.

LACKHOFF, M. et al. Photocatalytic Activity of Semicondutor-Modified cement-Influence of Semiconductor Type and Cement Ageing. Applied Catalysis B: Environmental, v. 43, p. 205-216, 2003.
MAGGOS, T. et al. Photocatalytic Degradation of $\mathrm{NO}_{\mathrm{x}}$ in a Pilot Street Canyon Configuration Using $\mathrm{TIO}_{2}$-Mortar Panels. Environment Monitoring Assessment, v. 136, 35-44, 2008.

MARANHÃO, F. Método Para Redução de Manchas nas Vedações Verticais Externas de Edifícios. São Paulo, 2009. 107 f. Tese (Doutorado em Engenharia Civil) - Escola Politécnica, Universidade de São Paulo, São Paulo, 2009.

MILLS, A.; WANG, J.; MCGRADY, M. Photocatalytic Oxidation of Soot by P25 $\mathrm{TIO}_{2}$ Films. Chemosphere, v. 64, 1032-1035, 2006.

OHAMA, Y.; VAN GEMERT, D. Application of Titanium Dioxide Photocatalysis to Construction Materials. State-of-the-art report of The RILEM Technical Committee, 2011.

POON, C. S.; CHEUNG, E. NO Removal Efficiency of Photocatalytic Paving Blocks Prepared with Recycled Materials. Construction and Building Materials, v. 21, n. 8, p. 1746-1753, 2007.

RAO, V.; SUBRAHMANYAM, M.; BOULE, P. Immobilized $\mathrm{TiO}_{2}$ Photocatalytuc During LongTerm Use: decrease in activity. Applied Catalysis B: Environmental, v. 49, p. 239-249, 2004.

VALLÉE, F. et al. Innovative Self-Cleaning and Depollution Façade Surface. In: CIB WORLD CONGRESS, 2004. Proceedings... 2004.

YU, J. C. Deactivation and Regeneration of Environmentally Exposed Titanium Dioxide $\left(\mathrm{TiO}_{2}\right)$ Based Products. Disponível em: <http://www.epd.gov.hk/epd/english/environmenti nhk/air/studyrpts/files/report-

updatedcb_paving_blocks_2003.pdf>. Acesso em: 27 ago. 2015.

\section{Agradecimentos}

Os autores agradecem a FAPESP pelo financiamento da pesquisa por meio do projeto FAPESP no 2011/03310-5, intitulado "Impacto do Envelhecimento Artificial Acelerado no Desempenho Fotocatalíticos de Revestimentos Autolimpantes de Edifícios". 
Guilherme Custódio Garcia Junior

Departamento de Engenharia | Universidade São Judas Tadeu | Rua Taquari, 546, Mooca | São Paulo - SP - Brasil | CEP 03166-000 | Tel.: (11) 2799-1999 Ramal 1751 | E-mail: garc@saojudas.br

\section{Eduardo de Azevedo Botter}

Departamento de Engenharia | Universidade São Judas Tadeu | E-mail: prof.botter@usjt.br

Flávio Leal Maranhão

Escola Politécnica | Universidade de São Paulo | Av. Prof. Almeida Prado, 83, Cidade Universitária | São Paulo - SP - Brasil | CEP 05508-900 | Tel.: (11) 3091-5459 | E-mail: prof.flaviomaranhao@usjt.br

\section{Revista Ambiente Construído}

Associação Nacional de Tecnologia do Ambiente Construído

Av. Osvaldo Aranha, $99-3^{\circ}$ andar, Centro

Porto Alegre - RS - Brasil

CEP $90035-190$

Telefone: +55 (51) 3308-4084

Fax: +55 (51) 3308-4054

www.seer.ufrgs.br/ambienteconstruido

E-mail: ambienteconstruido@ufrgs.br

320 Garcia Junior, G. C.; Botter, E. de A.; Maranhão, F. L. 